\title{
(2) OPEN ACCESS \\ Lack of effects of evidence-based, individualised counselling on medication use in insured patients with mild hypertension in China: a randomised controlled trial
}

\author{
Mengyang $\mathrm{Di},{ }^{1,2}$ Chen Mao, ${ }^{3}$ Zuyao Yang $(1),{ }^{2}$ Hong Ding, ${ }^{4}$ \\ Qu Liu, ${ }^{4}$ Shuiming Liu, ${ }^{4}$ Hongbo Guo, ${ }^{5}$ Kunhua Jiang, ${ }^{6}$ \\ Jinling Tang ${ }^{2,7}$
}

10.1136/bmjebm-2019-111197

For numbered affiliations see end of article.

Correspondence to: Professor Jinling Tang, Division of Epidemiology, School of Public Health and Primary Care, The Chinese University of Hong Kong, Hong Kong, China; jltang@ cuhk.edu.hk

Check for updates

(- Author(s) (or their employer(s)) 2020. Re-use permitted under $\mathrm{CC}$ BY-NC. No commercial re-use. See rights and permissions. Published by BMJ.

To cite: Di M, Mao C,

Yang Z, et al. BMJ

Evidence-Based Medicine

2020;25:102-108.

\section{Abstract}

Objective To evaluate whether evidence-based, individualised (EBI) counselling regarding hypertension and the treatment would affect medication use in insured patients with mild hypertension in China.

Methods We conducted a parallel-group, randomised controlled trial in two primary care centres in Shenzhen, a metropolitan city in China. Patients with mild primary hypertension, 10-year risk of cardiovascular diseases (CVDs) lower than 20\% and no history of CVDs were recruited and randomly allocated to two groups. EBI plus general counselling was provided to the intervention group and general counselling alone to the control group. EBI counselling included information on the 10-year CVD risk and treatment benefit in terms of absolute risk reduction estimated for each individual and information on average side effects and costs of antihypertensive drugs. The outcomes included use of antihypertensive drugs and adherence to the treatment at 6-month follow-up, with the former being primary outcome.

Results Two hundred and ten patients were recruited, with 103 and 107 allocated to the intervention and control groups, respectively. At baseline, $62.4 \%$ of the patients were taking antihypertensive drugs that were all covered by health insurance. At the end of 6-month follow-up, there was no statistically significant difference in the rate of medication use between the intervention group and the control group (65.0\% vs $57.9 \%$; OR=1.35, 95\% CI: 0.77 to 2.36). The difference in adherence rate between the two groups was not statistically significant either ( $43.7 \%$ vs $40.2 \%$; OR=1.15, 95\% CI 0.67 to 2.00]). The results were robust in sensitivity analyses that used different cutoffs to define the two outcomes.

Conclusions The EBI counselling by health educators other than the caring physicians had little impact on treatment choices and drugtaking behaviours in insured patients with mild primary hypertension in this study. It remains unclear whether EBI counselling would make a difference in uninsured patients, especially when conducted by the caring physicians.

Trial registration number ChiCTR-TRC-14004169.

\section{Key messages}

\section{What is already known about this} subject?

- It is important to provide relevant information to patients and take their values into account in clinical decision making, which can increase patient participation and help achieve patient-centred, personalised care.

- A Chinese survey found that the rate of willingness to pay completely out of pocket for antihypertensive drugs dropped substantially after evidencebased individualised counselling, assuming the general population were diagnosed with hypertension.

- It remains unclear whether evidencebased, individualised counselling regarding hypertension and its treatment would affect medication use in insured patients with mild hypertension in China.

\section{What are the new findings?}

- The evidence-based, individualised counselling by health educators other than the caring physicians did not reduce the rate of medication use, compared with usual care, in insured Chinese patients with mild primary hypertension.

- Compared with usual care, the evidence-based, individualised counselling did not reduce the adherence rate in insured hypertensive patients.

\section{Introduction}

Cardiovascular diseases (CVDs) that include coronary heart disease, cerebrovascular disease and peripheral arterial disease have become a major disease burden and accounted for approximately $30 \%$ of all deaths globally in 2012. ${ }^{1}$ Hypertension is an important and modifiable risk factor of CVDs. Antihypertensive drugs could reduce the risk of stroke and coronary heart disease by $46 \%$ and 21\%, respectively. ${ }^{2}$ 
Summary

\section{How might it impact on clinical practice in the} foreseeable future?

- Evidence-based, individualised counselling by health educators other than the caring physicians had little impact on treatment choices and drugtaking behaviours in insured patients with mild primary hypertension.

- Patients' drug-taking behaviours are not solely determined by their true needs but may be affected by multiple factors including insurance coverage, recommendations of practice guidelines and the people who inform them of the benefits and harms of treatment.

Currently, there are approximately 400 million hypertensive patients in China, ${ }^{3-5}$ posing a huge burden to the country's healthcare system. A large proportion of the patients have mild hypertension. There has been no consensus on whether to treat these patients or not, particularly those with relatively low risk of CVDs. For example, drug treatment was recommended for those patients by both the Eighth Joint National Committee guideline ${ }^{6}$ and the guideline of China ${ }^{7}$ but not by the the National Institute for Health and Care Excellence (NICE) guideline. ${ }^{8}$ This is partly due to the modest absolute benefit of drug treatment in terms of the number of CVDs preventable in such patients. In view of the small benefit and the potential adverse effects of treatment, patients with different socioeconomic status may hold different views towards the worthwhileness of taking antihypertensive treatment if they need to pay for it completely out of pocket. Thus, it is important to provide relevant information to patients and take their values into account in clinical decision making, which can increase patient participation and help achieve patient-centred, personalised care.

In fact, decision making informed by medical information has been widely recommended. ${ }^{9}{ }^{10}$ Previous studies showed that such patient-centred, informed and shared decision making was associated with higher rate of satisfaction with medical service and better health outcomes. ${ }^{112}$ In China, treatment used to be prescribed in a paternalistic approach, but the importance of shared decision making is now widely recognised. However, the implementation of shared decision making in outpatient service (as with the case in our study) is not satisfactory owing to limited time available for adequate communication between doctors and patients (as a result of the overwhelming outpatient visits and relatively small number of doctors in China), limited medical knowledge of patients, as well as other reasons. ${ }^{13}$ Previous studies suggested that involvement of a third person (eg, a nurse or junior doctor) to explain the medical information in detail to patients is helpful in achieving better shared decision making while saving the time of doctors. ${ }^{14}$

The key information needed for decision making include the benefit, harms and costs of the treatment, which should ideally be individualised and quantitative. ${ }^{15-19}$ A survey of general population in China ${ }^{20}$ studied whether counselling with such information made a difference to the participants' treatment choices, assuming that they were all diagnosed with hypertension. It showed that the rate of willingness to pay completely out of pocket for antihypertensive drugs dropped from 95\% to 23\% after the information was provided and explained, because the treatment was much less effective than the participants previously thought. This substantial decrease highlights the importance of providing evidence and engaging patients in order to make treatment decisions congruent with patients' values. Nonetheless, the large effect has not been replicated in real hypertensive patients and by measuring the actual use of medication rather than willingness to pay. In addition, antihypertensive drugs are now universally covered by health insurance in China ${ }^{21}$ as in many other countries, and patients do not need to pay out of their own pocket. Whether the large change in willingness to pay observed in the previous survey (conducted in general population and assuming that the treatment was paid for completely out of pocket) would still occur in today's real clinical practice in the country and consequently lead to less use of medication in real hypertensive patients remains unclear.

We therefore conducted this randomised controlled trial (RCT) to assess the effects of evidence-based, individualised (EBI) counselling on drug-taking behaviours in insured patients with mild hypertension in China.

\section{Methods}

The trial was registered at the Chinese Clinical Trial Registry before it started.

\section{Study population}

The participants were recruited between February and December in 2014 from two community health centres in Shenzhen, China, a city with a well-established primary care system. Patients eligible for inclusion were younger than 65 years, with mild hypertension (systolic blood pressure between $140 \mathrm{~mm} \mathrm{Hg}$ and $160 \mathrm{~mm}$ $\mathrm{Hg}$, diastolic blood pressure between $90 \mathrm{~mm} \mathrm{Hg}$ and $100 \mathrm{~mm} \mathrm{Hg}$ or both) and a 10-year CVD risk lower than 20\% and free of CVDs and diabetes mellitus. ${ }^{7822} 23$ This population was selected because their risk of CVD was generally low and the absolute benefit of drug treatment small among them. Withholding treatment temporarily from them would not cause much harm (eg, subjecting them to high risk of CVD), if any, and can be considered as relatively safe and ethically justifiable. This is also why the recommendations on antihypertensive treatment for them have been inconsistent. ${ }^{6-8}$ Patients' eligibility was evaluated by the physicians at the study sites, and the health educator of this project is a qualified doctor with a degree of doctor of medicine. All the patients had signed informed consents prior to recruitment.

\section{Randomisation}

An independent statistician generated a random sequence using Stata V.10.0. ${ }^{24}$ We randomly allocated patients to two paralleled groups with a ratio approximately $1: 1$. We concealed the random numbers in opaque, sealed and sequentially numbered envelopes, which were kept in a locked drawer. A nurse in charge of patients' allocation released random numbers sequentially only after new eligible patients were enrolled. It was infeasible to mask patients and the health educator in counselling arrangement. Nonetheless, we did not inform the patients and the physicians the hypothesis of the study, and patient allocation was deliberately withheld from the physicians.

\section{Intervention and implementation}

The information was delivered through counselling, as it would be the most effective way to ensure patients receive all the information to be conveyed, and possibly best simulated patient-physician interaction in daily practice. Patients in the intervention group received EBI counselling on top of general counselling about lifestyle modification, while those in the control group received general counselling alone. 
The EBI information package was developed in compliance with the recommendations of International Patient Decision Aids Standards Collaboration ${ }^{15-19}$ and through panel discussion of one cardiologist, three epidemiologists, two patients and one health educator. The key contents included: (1) 10-year CVD risk in the absence of antihypertensive drug treatment and absolute risk reduction (ARR) by drug treatment of a given patient and (2) information on the average side effects and costs of the drugs. The 10-year CVD risk was estimated by using the Fuwai equation $^{25}$ that incorporated the risk factors of an individual patient, such as age, gender, blood pressure (BP), total cholesterol and smoking habit and was suitable for Chinese population. The ARR was calculated by multiplying the 10-year CVD risk and the relative risk reduction of $26 \% .{ }^{2}$ Therefore, the 10-year CVD risk and ARR both varied considerably among individual patients. We further adapted the logic, language and medical terms used in the package after rehearsal in two healthy people without medical background and four hypertensive patients.

The health educator provided the counselling face to face and distributed a leaflet containing the key message to patients at the end of counselling. The intervention was reinforced with a concise version of counselling through telephone 1 week later. We took several measures to ensure consistency in the amount of information communicated and ways of expression or explanation. They included developing an operation manual to standardise the delivery of information, training the health educator to strictly follow the manual and having only one health educator throughout the study. We used descriptions as factual and objective as possible in the manual to avoid judgmental statements or personal interpretations.

We monitored the process of counselling by examining changes in knowledge of patients in the intervention group. We evaluated potential contaminations and main external factors that could possibly influence the effects of counselling. At the last follow-up, we provided individualised information to patients in the control group as well and asked whether and how they would do if they had obtained the information earlier. We also asked patients in both groups whether they had communicated their 10-year CVD risk and ARR with doctors, and if yes, the doctors' attitude towards the information and medication use.

\section{Outcomes}

We used actual treatment rate as the primary outcome and adherence to treatment and satisfaction rate with treatment choices as the secondary ones to estimate the effect of counselling. Previous studies have shown that concerns about adverse effects were a main reason for people's not taking their prescribed medicines. ${ }^{26}$ We defined patients on antihypertensive treatment as those taking drugs for at least 10 days in the past 2 weeks. ${ }^{27}{ }^{28}$ For adherence to treatment, the patients were asked at each follow-up visit to recall the drug-taking status during the past week, including the days of drug taking in the past week, times of drug taking on average per day and the average number of pills taken for each time. The total number of pills taken in the past week was derived based on these information, and the percentage of prescribed pills taken by them was calculated as the total weekly number of pills actually taken divided by the total number of pills prescribed for a week. ${ }^{29-32}$ Good adherence was considered to have been achieved if the proportion was $80 \%$ or above. ${ }^{33}$ We also asked the participants at the last follow-up whether they were satisfied with their current treatment choices of either on treatment or not. The satisfaction rate was calculated as the number of patients who were satisfied with their treatment choice divided by the total number of patients randomised in each group.

\section{Data collection}

The research assistants or the health educator conducted the baseline interview after patient recruitment. We collected demographic characteristics (such as gender and age), family history, lifestyle factors related to CVD (such as smoking, drinking and physical exercise), antihypertensive drug use and prescription information, and patients' knowledge and attitude about hypertension and antihypertensive treatment. Classification of physical exercise was adapted from that applied in the National Nutrition Survey. ${ }^{27}$ Current physical exercise was defined as participating physical exercise for over 20 min each time on a regular basis for the purpose of body fit. Physical exercise rate was calculated as the number of current physical exercise participants divided by the total number of subjects in each group. For the survey on 'knowledge', the patients were asked about their perception of the ultimate goal of antihypertensive treatment (eg, for reducing BP itself or for preventing CVD), the 10-year CVD risk in the absence of antihypertensive treatment, the absolute benefit of antihypertensive treatment in terms of number of CVD events prevented in every 100 patients taking the treatment and the risk of adverse effects caused by treatment. For the survey on 'attitude', the patients were asked about their attitude towards antihypertensive treatment (ie, would or would not receive) and the reasons behind. They might provide multiple reasons for their choices. The health educator measured BP, weight and height by following the protocols of measuring biological risk factors for Fuwai equation $^{25}$ wherever possible. The health educator collected outcome data at 2 weeks, 3 months and 6 months after counselling through telephone.

\section{Sample size and statistical analyses}

We applied the treatment rate of 75\% in both groups from the pilot trial and anticipated a difference of 20\% between groups, which would be large enough for clinical attention. According to the previous survey conducted by our team in China, a difference of $20 \%$ would be conservative as it is lower than one-third of the difference the counselling was anticipated to make in hypothetical patients who were supposed to pay out of pocket. ${ }^{20}$ To test for such a magnitude of effect at a significance level of 0.05 , a power of 0.8 and a rate of loss to follow-up of 10\%, a sample size of 200 was required.

We analysed the outcome data by following the intentionto-treat principle, assuming that patients with missing data did not change their treatment choices from baseline. We calculated the treatment rates in both groups at each follow-up and used $\chi^{2}$ test to examine the difference between groups. We also calculated OR and 95\% CI as the estimate of effect size of EBI counselling, with general counselling group as reference. The data on adherence to treatment were analysed similarly. The effect at 6-month follow-up was regarded the most important. In sensitivity analyses, different cut-offs were employed to define medication use and good adherence, and the effect sizes at 6-month follow-up were recalculated to examine whether the results from main analyses were robust or not.

\section{Results}

Between February and June in 2014 (as shown in the figure 1), 352 patients were assessed for eligibility and 210 underwent randomisation. One hundred and three patients were assigned to the intervention group and 107 to the control group. Follow-up 
was carried out through December in 2014. During the follow-up, eight patients withdrew their consent because they considered the counselling and follow-up as unhelpful in BP control, and 10 patients could not be reached despite multiple telephone contacts. The overall attrition rate was $8.57 \%$.

The study process was carefully monitored. The counselling was fully implemented in over 90\% patients in both groups, respectively. Patients in the intervention group had significantly improved knowledge level of the key information after the EBI counselling. No adverse events caused by intervention were reported by the participants; however, we found that the intervention seemed to have a slight negative effect on physical exercise rate $(68.9 \%$ in the intervention group vs $80.4 \%$ in the control group at last follow-up, $\mathrm{p}=0.056$ ). The level of potential contamination was low; by the last follow-up visit, only one patient in the control group indicated that he had obtained the 10-year CVD risk and ARR from his physician. Fewer than 10 patients in each group had ever communicated with physicians the key contents of EBI counselling and necessity of medication use. The actual interval from counselling to each follow-up visit was close to the planned interval, respectively.

The baseline characteristics of patients were shown in table 1 . The mean age was 54.3 years. The proportion of male participants was $49.0 \%$. Antihypertensive medications were covered by health insurance in all the patients, and 131 (62.4\%) patients were currently taking antihypertensive drugs. The patients overestimated their 10year CVD risk and ARR by over 4 and 14 times, respectively.

All the patients enrolled were included for analyses. At 6-month follow-up, 67 (65.0\%) and 62 (57.9\%) patients in the intervention and control groups, respectively, were taking antihypertensive drugs (OR $1.35,95 \% \mathrm{CI} 0.77$ to 2.36 , p value $=0.290$ ), and $45(43.7 \%)$ and $43(40.2 \%)$ patients, respectively, had good adherence to the treatment (OR 1.15, 95\% CI 0.67 to 2.00, p value $=0.607$ ). The difference in both outcomes between the intervention and control groups was not statistically significant. The data collected at the first two follow-up visits showed consistent results (table 2). In sensitivity analyses, the effects of intervention remained similar when different cut-off values for defining medication use and good adherence were employed (online supplements 3 and 4). None of the results was statistically significant.

The between-group difference in the proportion of participants who felt satisfied with their treatment choices $(63.1 \%$ in intervention, 57.9\% in control) was not statistically significant either. The majority of patients taking prescribed drugs said that they did not want to give up their right to take the drugs for (almost) free. Around one-third said they took the prescribed drugs because the outcome of untreated hypertension (eg, stroke) was severe and taking drugs reassured them. Among those who were not taking prescribed drugs, more than half expressed concerns about the adverse effects, especially severe adverse effects and drug dependence; one respondent did not take drugs for 'the risk of CVD was low' and two respondents for 'the ARR of treatment was small'.

\section{Discussion}

This study showed that the EBI counselling had little effect on drug-taking behaviours of patients with mild hypertension for whom medications were covered by medical insurance. This is in drastic contrast with what was anticipated from the large effect suggested in a previous survey of hypothetical hypertensive patients who had to pay out of their own pocket. ${ }^{10}$ However, our results were largely consistent with similar $\mathrm{RCTs}^{34-37}$ on medication of hypertension, hyperlipidaemia and/or hyperglycaemia in populations for whom these medications are free.

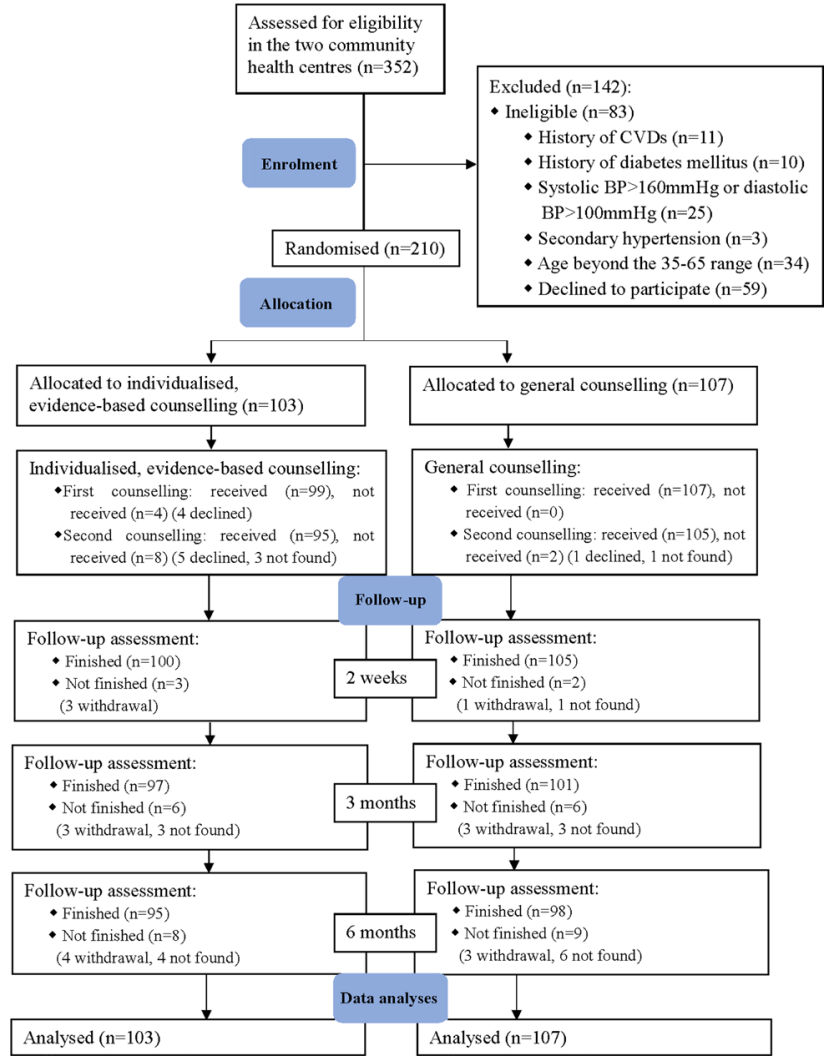

Figure 1 Participant flow diagram. BP, blood pressure; CVD, cardiovascular disease.

The discrepancy in the results between our previous survey ${ }^{10}$ and this trial is unlikely to be explained by the different study design, outcomes and disease status of the people in the two studies (table 3). The treatment rate did not change $(66.0 \%$ at baseline to $65.0 \%$ ) 6 months after the EBI counselling in the intervention group of our study. Very similar pre-post difference was found in other RCTs as well. The same conclusion was drawn when the willingness to take medication (the primary outcome in the previous survey) was used from this study.

These findings suggest that the method of payment may be an explanation for the lack of influence of counselling on medication use. In other words, after receiving the EBI information, the willingness to pay or medication use substantially decreased in uninsured patient populations while remained unchanged if medication was covered by health insurance. The assumption is supported by observations from other studies ${ }^{38-42}$ that both willingness to treat ${ }^{42}$ and use of medical service ${ }^{41}$ was substantively decreased as the out-of-pocket payment rate was increased and that the proportion of patients with effective BP control was also significantly higher in medically insured populations. ${ }^{38-40}$

The reasons provided by the patients for drug taking give further support for the above assumption. The majority patients in our trial said that they did not want to 'give up their entitled right that they believed they should have' of taking drugs for (almost) free. Otherwise, it would be considered as a potential loss. It suggests importantly that insurance coverage is a determinant of medication use behaviours in insured populations, whereas benefit and harms of treatment and patients' needs do not make much a difference although they should have.

Another possible interpretation for the lack of effect of the EBI information on medication use is parental care practice in 


\begin{tabular}{|c|c|c|c|}
\hline Characteristics & $\begin{array}{l}\text { Overall } \\
(n=210)\end{array}$ & $\begin{array}{l}\text { Control } \\
(\mathrm{n}=107)\end{array}$ & $\begin{array}{l}\text { Intervention } \\
(\mathrm{n}=103)\end{array}$ \\
\hline \multicolumn{4}{|l|}{ Demographic characteristics } \\
\hline Males, n (\%) & $103(49.0)$ & $52(48.6)$ & $51(49.5)$ \\
\hline Age at recruitment, mean (SD), year & $54.3(7.8)$ & $54.5(7.8)$ & $54.1(7.8)$ \\
\hline Education more than high school, n (\%) & $56(26.7)$ & $27(25.2)$ & $29(28.2)$ \\
\hline Insurance in Shenzhen, $\mathrm{n}(\%)$ & $120(57.1)$ & $60(56.1)$ & $60(58.3)$ \\
\hline \multicolumn{4}{|l|}{ Modifiable CVD risk factors } \\
\hline BMI, mean (SD), kg/m² & $25.2(3.2)$ & $24.7(3.0)$ & $25.7(3.3)$ \\
\hline Systolic blood pressure, mean (SD), mmHg & $133.4(12.2)$ & $132.5(12.4)$ & $134.6(11.9)$ \\
\hline Diastolic blood pressure, mean (SD), $\mathrm{mmHg}$ & $88.0(9.4)$ & $87.0(9.5)$ & $89.0(9.2)$ \\
\hline Total cholesterol, mean (SD), mmol/l & $5.3(1.0)$ & $5.3(0.9)$ & $5.3(1.0)$ \\
\hline 10-year CVD risk estimated, median (IQR), \% & $7.0(4.0,11.0)$ & $7.0(4.0,12.0)$ & $7.0(4.0,11.0)$ \\
\hline \multicolumn{4}{|l|}{ Family history } \\
\hline Hypertension, n (\%) & $161(76.7)$ & $81(75.7)$ & $80(77.7)$ \\
\hline CVD history, $\mathrm{n}(\%)$ & $23(11.0)$ & $11(10.3)$ & $12(11.8)^{2}$ \\
\hline \multicolumn{4}{|l|}{ Medical history related to hypertension } \\
\hline Types of medicine taken, median (IQR) & $1.0(1.0,2.0)$ & $1.0(0.3,2.0)$ & $1.0(1.0,2.0)$ \\
\hline Types of antihypertensive medicine taken median (IQR) & $1.0(1.0,2.0)$ & $1.0(1.0,2.0)$ & $1.0(1.0,1.5)$ \\
\hline Years since hypertension diagnosed, median (IQR), year & $4.7(2.2,10.2)$ & $5.3(2.4,10.1)$ & $4.2(2.0,10.1)$ \\
\hline Years of taking antihypertensive medicines, median (IQR), year & $4.1(1.8,9.7)$ & $4.8(1.9,9.8)$ & $3.1(1.5,7.9)$ \\
\hline \multicolumn{4}{|l|}{ Knowledge about CVDs } \\
\hline Correctly answered all questions, $\mathrm{n}(\%)$ & $19(9.1)$ & $10(9.4)$ & $9(8.8)$ \\
\hline Self-estimated 10 year CVD risk, median (IQR), \% & $50.0(50.0,75.0)$ & $50.0(30.0,70.0)$ & $60.0(50.0,80.0)$ \\
\hline $\begin{array}{l}\text { Self-estimated absolute risk reduction by antihypertensive medicines, median (IQR), } \\
\%\end{array}$ & $30.0(20.0,40.0)$ & $30.0(20.0,37.5)$ & $30.0(20.0,50.0)$ \\
\hline \multicolumn{4}{|l|}{ History of antihypertensive treatment } \\
\hline Taking medications, n (\%) & $131(62.4)$ & $63(58.9)$ & $68(66.0)$ \\
\hline Good adherence, $\mathrm{n}(\%)$ & $91(43.4)$ & $43(40.2)$ & $48(46.6)$ \\
\hline \multicolumn{4}{|l|}{ CVD-related lifestyle factors } \\
\hline Smoking, n (\%) & $31(14.8)$ & $20(18.7)$ & $11(10.7)$ \\
\hline Alcohol drinking, n (\%) & $31(14.7)$ & $12(11.2)$ & $19(18.4)$ \\
\hline Physical exercise, $\mathrm{n}(\%)$ & $142(67.6)$ & $76(71.0)$ & $66(64.1)$ \\
\hline High salt intake, $n(\%)$ & $56(32.6)$ & $26(29.5)$ & $30(35.7)$ \\
\hline High fat intake, n (\%) & $43(25.3)$ & $18(20.5)$ & $25(30.5)$ \\
\hline
\end{tabular}

BMI, body mass index; CVD, cardiovascular disease; IQR, interquartile range; SD, standard deviation.

medicine. Most patients in our trial still preferred 'following physicians' suggestions' to making decisions by themselves, despite sufficient information provided to and understood by the patients. Had it be delivered by physicians, EBI might lead to some changes in patients' behaviours. However, physicians (including those in this trial) in general feel strongly that they are obliged to follow the practice guideline in China. It can thus be inferred that patients' true needs and willingness to take medications may be

\begin{tabular}{|c|c|c|c|c|c|}
\hline \multirow[b]{2}{*}{ Outcome variables } & \multicolumn{2}{|l|}{ Control } & \multicolumn{2}{|c|}{ Intervention } & \multirow[b]{2}{*}{ OR $(95 \% \mathrm{Cl})$} \\
\hline & Number & Events (\%)* & Number & Events (\%)* & \\
\hline \multicolumn{6}{|c|}{ Use of antihypertensive drugs } \\
\hline Baseline & 107 & $63(58.9)$ & 103 & $68(66.0)$ & 1.36 (0.77 to 2.38$)$ \\
\hline 2-week follow-up & 105 & $63(58.9)$ & 100 & $68(66.0)$ & $1.36(0.77$ to 2.38$)$ \\
\hline 3-month follow-up & 101 & $69(64.5)$ & 97 & $67(65.0)$ & $1.02(0.58$ to 1.81$)$ \\
\hline 6-month follow-up & 98 & $62(57.9)$ & 95 & $67(65.0)$ & 1.35 (0.77 to 2.36$)$ \\
\hline \multicolumn{6}{|l|}{ Good adherence } \\
\hline Baseline & 107 & $43(40.2)$ & 103 & $48(46.6)$ & $1.30(0.75$ to 2.24$)$ \\
\hline 2-week follow-up & 105 & $44(41.1)$ & 100 & $50(49.5)$ & 1.35 (0.78 to 2.33$)$ \\
\hline 3-month follow-up & 101 & $50(46.7)$ & 97 & $45(43.7)$ & $0.88(0.51$ to 1.52$)$ \\
\hline 6-month follow-up & 98 & $43(40.2)$ & 95 & $45(43.7)$ & 1.15 (0.67 to 2.00$)$ \\
\hline
\end{tabular}

*Percentages were calculated following the 'intention-to-treat' principle.

$\mathrm{Cl}$, confidence interval; $\mathrm{OR}$, odds ratio. 
Table 3 Differences in study design and context between a previous highly relevant survey and the current randomised controlled trial

\begin{tabular}{|c|c|c|}
\hline Characteristics & The previous survey & This trial \\
\hline Study design & Pre-post comparison & $\begin{array}{l}\text { Paralleled } \\
\text { comparison }\end{array}$ \\
\hline Outcomes of interest & $\begin{array}{l}\text { Willingness to pay for/to } \\
\text { take the treatment }\end{array}$ & $\begin{array}{l}\text { Actual medication } \\
\text { use }\end{array}$ \\
\hline $\begin{array}{l}\text { Percent with } \\
\text { hypertension }\end{array}$ & 14.9 & 100 \\
\hline Method of payment & Out of the pocket & Insurance \\
\hline
\end{tabular}

considerably distorted in decision making where parental care is the main practice model and guidelines have strong influence on doctors' practice.

The results of this study and the above discussions suggest importantly that in conventional medical practice, patient drugtaking behaviours seem to be dominated by insurance coverage and recommendations of practice guidelines, other than by evidence on benefits and harms of treatment and patients' true needs. ${ }^{43} 44$ Therefore, it is ultimately important to engage (potential) patients in making insurance policies and practice guidelines, so that their true needs and views about the value of a treatment can be more faithfully reflected. For the same reason, informing patients with evidence may not make any difference to patients' treatment choices in current medical practice where physicians feel strongly they have to adhere to the guidelines.

This study has several limitations. First, it may be subjected to reporting bias, which is a common concern in self-reported data. The commonly used methods to evaluate medical adherence include prescription refills, patients' scales and self-reporting, among others. ${ }^{33456}$ We did not use the prescription refills method because the antihypertensive prescription could be refilled at any hospitals, primary care centres or even pharmacies in the city where our study was carried out, and the network among the hospitals, centres and pharmacies had not been established so that we could not check all the refills from different places for a patient. As a result, the prescription history recorded solely in the community health centres where this study was conducted was accessible and would underestimate the actual refills. The patients' scales were not used mainly because they had not been well validated for studying adherence to antihypertensive drugs in Chinese populations. Moreover, the scores obtained could not reflect the number of pills taken during the investigated period. Thus, the self-reporting method, which was once recommended in several articles, ${ }^{29-32}$ was chosen in this study. Our topic was however not stigmatic. ${ }^{4-49}$ We also told the patients clearly that it was their own choices whether to take the drugs or not and there were no right or wrong answers to the questions we asked in the questionnaire. This helped reduce the possibility that patients deliberately gave an answer to please the investigators. ${ }^{50-53}$ Second, the counselling was provided by health educators instead of the caring physicians of the patients in the community health centres, who would be more authoritative in informing the patient and affecting their behaviours. It remains unclear whether patients' drug-taking behaviours would change had the EBI counselling been provided by the caring physicians.

In conclusion, the EBI counselling by health educators other than physicians made little change to treatment choices and drugtaking behaviours in insured patients with mild hypertension in this study. It remains unclear whether EBI counselling would make a difference in uninsured patients, especially when conducted by the caring physicians.
Author affiliations

${ }^{1}$ Department of Medicine, Rhode Island Hospital, Brown University, Providence, Rhode Island, USA

${ }^{2}$ Division of Epidemiology, School of Public Health and Primary Care, Chinese University of Hong Kong, New Territories, Hong Kong ${ }^{3}$ Department of Epidemiology, School of Public Health, Southern Medical University, Guangzhou, China

${ }^{4}$ Longgang Center for Disease Control and Prevention, Shenzhen, China

${ }^{5}$ Central City Community Healthcare Centre, Longgang People's Hospital, Shenzhen, China

${ }^{6}$ Ziwei Garden Community Healthcare Centre, Longgang People's Hospital, Shenzhen, China

${ }^{7}$ Shenzhen Key Laboratory for Health Risk Analysis, Shenzhen Research Institute of The Chinese University of Hong Kong, Shenzhen, China

Funding The authors have not declared a specific grant for this research from any funding agency in the public, commercial or not-for-profit sectors.

Competing interests None declared.

Patient consent for publication Not required.

Provenance and peer review Not commissioned; externally peer reviewed.

Data availability statement Data are available on reasonable request.

Open access This is an open access article distributed in accordance with the Creative Commons Attribution Non Commercial (CC BY-NC 4.0) license, which permits others to distribute, remix, adapt, build upon this work non-commercially, and license their derivative works on different terms, provided the original work is properly cited, appropriate credit is given, any changes made indicated, and the use is non-commercial. See: http://creativecommons.org/licenses/by-nc/4.0/.

\section{ORCID iD}

Zuyao Yang http://orcid.org/0000-0003-2386-2431

\section{References}

1 World Health Organization. Global status report on noncommunicable diseases 2010.Geneva: World Health Organization, 2011. Available: http:// www.who.int/nmh/publications/ncd_report_full_en.pdf [Accessed 27 Sept 2014].

2. Law MR, Morris JK, Wald NJ. Use of blood pressure lowering drugs in the prevention of cardiovascular disease: meta-analysis of 147 randomised trials in the context of expectations from prospective epidemiological studies. BMJ 2009;338:b1665.

3. Wang Y, Peng X, Nie X, et al. Burden of hypertension in China over the past decades: systematic analysis of prevalence, treatment and control of hypertension. Eur J Prev Cardiol 2016;23:792-800.

4. Wu Y, Huxley R, Li L, et al. Prevalence, awareness, treatment, and control of hypertension in China: data from the China national nutrition and health survey 2002. Circulation 2008;118:2679-86.

5. Feng XL, Pang M, Beard J. Health system strengthening and hypertension awareness, treatment and control: data from the China health and retirement longitudinal study. Bull World Health Organ 2014;92:29-41.

6. James PA, Oparil S, Carter BL, et al. 2014 evidence-based guideline for the management of high blood pressure in adults: report from the panel members appointed to the Eighth Joint National Committee (JNC 8). JAMA 2014;311:507-20.

7. Liu LS, Writing Group of 2010 Chinese Guidelines for the Management of Hypertension. [2010 Chinese guidelines for the management of hypertension]. Zhonghua Xin Xue Guan Bing Za Zhi 2011;39:579-615.

8. The National Institute for Health and Care Excellence. Hypertension: clinical management of primary hypertension in adults. Available: http:// www.nice.org.uk/nicemedia/live/13561/56008/56008.pdf 
9. Bardes CL. Defining "Patient-Centered Medicine". N Engl J Med 2012;366:782-3.

10. Bergeson SC, Dean JD. A systems approach to patient-centered care. JAMA 2006;296:2848-51.

11. Shay LA, Lafata JE. Where is the evidence? A systematic review of shared decision making and patient outcomes. Med Decis Making 2015;35:114-31.

12. Sepucha KR, Atlas SJ, Chang Y, et al. Informed, patient-centered decisions associated with better health outcomes in orthopedics: prospective cohort study. Med Decis Making 2018;38:1018-26.

13. Huang $R$, Yang $X$, Song $X$, et al. The current status and expectation of shared-decision making in Chinese patients with cardiovascular disease. Med Philosophy 2017;38:1-6.

14. Huang R, Song $\mathrm{X}$, Wu J, et al. Assessing the feasibility and quality of shared decision making in China: evaluating a clinical encounter intervention for Chinese patients. Pat Prefer Adherence 2016;10:2341-50.

15. Informed Medical Decisions Foundation. Healthwise research and advocacy. What is shared decision making? Available: http://www.info rmedmedicaldecisions.org/what-is-shared-decision-making/ [Accessed 28 Sept 2014].

16. Stacey D, Bennett CL, Barry MJ, et al. Decision AIDS for people facing health treatment or screening decisions. Cochrane Database Syst Rev $2011 ; 10$.

17. Stacey D, Legare F, Col NF, et al. Decision AIDS for people facing health treatment or screening decisions. Cochrane Database Syst Rev 2014;1.

18 Elwyn G, O'Connor A, Stacey D, et al. Developing a quality criteria framework for patient decision AIDS: online international Delphi consensus process. BMJ 2006;333.

19. Joseph-Williams N, Newcombe R, Politi M, et al. Toward minimum standards for certifying patient decision AIDS: a modified Delphi consensus process. Med Decis Making 2013;34:699-710.

20. Tang JL, Wang WZ, An JG, et al. How willing are the public to pay for anti-hypertensive drugs for primary prevention of cardiovascular disease: a survey in a Chinese City. Int J Epidemiol 2010;39:244-54.

21. National essential medicines list 2012. Available: http://www.moh.gov.cn/ mohywzc/s3580/201303/f01fcc9623284509953620abc2ab189e/files/961c fc3a86584f8888e9140b1c208438.pdf [Accessed 12 Jun 2015].

22. Gonzalez-Clemente JM, Palma S, Arroyo J, et al. Is diabetes mellitus a coronary heart disease equivalent? Results of a meta-analysis of prospective studies. Rev Esp Cardiol 2007;60:1167-76.

23. Juutilainen A, Lehto S, Ronnemaa T, et al. Type 2 diabetes as a "coronary heart disease equivalent": an 18-year prospective population-based study in Finnish subjects. Diabetes Care 2005;28:2901-7.

24. Wu CL, Wang L, Li WB. Randomization of clinical trial and its application of Stata. Chin J Evid-based Med 2013;13:242-4.

25. Wu Y, Liu X, Li X, et al. Estimation of 10-year risk of fatal and nonfatal ischemic cardiovascular diseases in Chinese adults. Circulation 2006;114:2217-25.

26. Pound P, Britten N, Morgan M, et al. Resisting medicines: a synthesis of qualitative studies of medicine taking. Soc Sci Med 2005;61:133-55.

27. Technical working standards for China national nutrition and health survey in 2002. Available: http://wenku.baidu.com/view/5b20f7661ed9 ad51f01df212.html [Accessed 16 Dec 2013].

28. LiLM, Rao KQ, Kong LZ, et al. [A description on the Chinese national nutrition and health survey in 2002]. Zhonghua Liu Xing Bing Xue Za Zhi 2005;26:478-84.

29. Fletcher SW, Pappius EM, Harper SJ. Measurement of medication compliance in a clinical setting. Comparison of three methods in patients prescribed digoxin. Arch Intern Med 1979;139:635-8.

30. Gonzalez JS, Schneider HE, Wexler DJ, et al. Validity of medication adherence self-reports in adults with type 2 diabetes. Diabetes Care 2013;36:831-7.

31. Jerant A, DiMatteo R, Arnsten J, et al. Self-Report adherence measures in chronic illness: retest reliability and predictive validity. Med Care 2008;46:1134-9.
32. Stephenson BJ, Rowe BH, Haynes RB, et al. The rational clinical examination. Is this patient taking the treatment as prescribed? JAMA 1993;269:2779-81.

33. PM H, Bryson CL, Rumsfeld JS. Medication adherence: its importance in cardiovascular outcomes. Circulation 2009;119:3028-35.

34. Denig P, Schuling J, Haaijer-Ruskamp F, et al. Effects of a patient oriented decision aid for prioritising treatment goals in diabetes: pragmatic randomised controlled trial. BMJ 2014;349:g5651.

35. Montgomery AA, Fahey T, Peters TJ. A factorial randomised controlled trial of decision analysis and an information video plus leaflet for newly diagnosed hypertensive patients. Br J Gen Pract 2003;53:446-53.

36. Sheridan SL, Shadle J, Simpson RJ, et al. The impact of a decision aid about heart disease prevention on patients' discussions with their doctor and their plans for prevention: a pilot randomized trial. BMC Health Serv Res 2006;6:121.

37. Weymiller AJ, Montori VM, Jones LA, et al. Helping patients with type 2 diabetes mellitus make treatment decisions: statin choice randomized trial. Arch Intern Med 2007;167:1076-82.

38. Duru 0, Vargas R, Kermah D, et al. Health insurance status and hypertension monitoring and control in the United States. Am J Hypertens 2007;20:348-53.

39. Gandelman G, Aronow WS, Varma R. Prevalence of adequate blood pressure control in self-pay or Medicare patients versus Medicaid or private insurance patients with systemic hypertension followed in a university cardiology or general medicine clinic. Am J Cardiol 2004;94:815-6.

40. Maimaris W, Paty J, Perel P, et al. The influence of health systems on hypertension awareness, treatment, and control: a systematic literature review. PLoS Med 2013;10:e1001490.

41. Manning WG, Newhouse JP, Duan N, et al. Health insurance and the demand for medical care: evidence from a randomized experiment. Am Econ Rev 1987;77:251-77.

42. Sinsky CA, Foreman-Hoffman V, Cram P. The impact of expressions of treatment efficacy and out-of-pocket expenses on patient and physician interest in osteoporosis treatment: implications for pay-for-performance programs. J Gen Intern Med 2008;23:164-8.

43 Tang JL, Glasziou P. Essentials in evidence-based medicine. Beijing: Peking University Medical Press, 2010.

44. Haynes RB, Devereaux PJ, Guyatt GH. Physicians' and patients' choices in evidence based practice. BMJ 2002;324:1350.

45. Krousel-Wood MA, Muntner P, Islam T, et al. Barriers to and determinants of medication adherence in hypertension management: perspective of the cohort study of medication adherence among older adults. Med Clin North Am 2009;93:753-69.

46. Hyman DJ, Pavlik V. Medication adherence and resistant hypertension. $J$ Hum Hypertens 2015;29:213-8.

52 Kelly CA, Soler-Hampejsek E, Mensch BS, et al. Social desirability bias in sexual behavior reporting: evidence from an interview mode experiment in rural Malawi. Int Perspect Sex Reprod Health 2013;39:14 -21 .

48. Nolte S, Elsworth GR, Osborne RH. Absence of social desirability bias in the evaluation of chronic disease self-management interventions. Health Qual Life Outcomes 2013;11:114.

49. Beauclair R, Meng F, Deprez N, et al. Evaluating audio computer assisted self-interviews in urban South African communities: evidence for good suitability and reduced social desirability bias of a cross-sectional survey on sexual behaviour. BMC Med Res Methodol 2013;13:11.

50. Fisher RJ. Social desirability bias and the validity of indirect Questioning. J Consum Res 1993;20:303-15.

51. Grimm P. Social desirability bias. Wiley International Encyclopedia of Marketing, 2010.

57 Adams SA, Matthews CE, Ebbeling CB, et al. The effect of social desirability and social approval on self-reports of physical activity. Am J Epidemiol 2005;161:389-98.

53. Kaushal K. Social desirability bias in face to face interviews. J Postgrad Med 2014;60:415-6. 